\title{
Histopathological correlation of abnormal uterine bleeding in perimenopausal women
}

\author{
Prasanna Byna*, Shireesha Siddula, Swathi Kolli, Mahaboob V. Shaik
}

Department of Obstetrics \& Gynaecology, Narayana Medical College \& Hospital, Nellore, Andhra Pradesh, India

Received: 24 September 2015

Revised: 05 September 2015

Accepted: 29 October 2015

\author{
*Correspondence: \\ Dr. Prasanna Byna, \\ E-mail: research.nmch@rediffmail.com
}

Copyright: (c) the author(s), publisher and licensee Medip Academy. This is an open-access article distributed under the terms of the Creative Commons Attribution Non-Commercial License, which permits unrestricted non-commercial use, distribution, and reproduction in any medium, provided the original work is properly cited.

\begin{abstract}
Background: Current study designed to identify the causes of abnormal uterine bleeding( AUB) in perimenopausal women and also to correlate with their histopathological examination.

Methods: A prospective study of 65 perimenopausal women with complaint of AUB with age group ranging from 40 to 1 year within menopause those are attending to department of gynaecology of Narayana Medical College \& Hospital, Nellore. Clinical examinations between the parameters were analysed. Histopathological examination report was also correlated with clinical examination and ultrasonography.

Results: Out of 65 women, $11(16.9 \%)$ were primiparas, $36(55.38 \%)$ were para 2, $18(27.69 \%)$ were para 3 and above. The frequent menstrual abnormality seen in perimenopausal women is heavy menstrual bleeding i.e., $41(63 \%)$ women out of 65 women, $14(21.53 \%)$ had polymenorrhoea, $9(13.84 \%)$ had oligomenorrhea, $6(9.23 \%)$ had postmenopausal bleeding, $4(6.15 \%)$ had intermenstrual spotting. Most common type of endometrial pattern is proliferative endometrium. Out of 65 perimenopausal women, $23(35.38 \%)$ had proliferative type of endometrium, 20 $(30.76 \%)$ women had secretory pattern, 9 (13.84\%) had typical simple endometrial hyperplasia, $4(6.15 \%)$ had atypical simple endometrial hyperplasia, $3(4.61 \%)$ had adenomyomatous polyp, and $6(9.2 \%)$ women had irregular ripening.

Conclusions: The present study shows that Histopathological examination is mandatory in all cases of AUB in perimenopausal age. $66.14 \%$ had benign pathology which can be managed by hormonal therapy or conservative surgical modalities which alleviates need for unnecessary hysterectomy.
\end{abstract}

Keywords: Abnormal uterine bleeding, Histopathology, Dysfunctional uterine bleeding

\section{INTRODUCTION}

Abnormal uterine bleeding (AUB) is defined as any deviation in terms of cycle, duration of bleeding, amount of blood loss or combination of all. It includes both DUB (i.e. due to functional causes) and bleeding from structural causes like Fibroids, Polyp and due to endometrial pathology. ${ }^{1} \quad$ Endometrium represents a plethora of changes that balanced by the complex interplay of endogenous steroids and other factor. ${ }^{2}$

WHO defines perimenopause as the period 2 to 8 years preceding the menopause and 1 year after the final menses. It generally occurs around 40 to 50 years and last for 4 years. $^{2}$ There is a depletion of antral follicle count in the ovary leading to erratic folliculogenesis and frequent anovulation. In many perimenopausal women AUB is due to endometrial pathology, which requires proper evaluation and diagnosis. The histological pattern of endometrium in these women ranges from simple endometrial hyperplasia to endometrial carcinoma which justifies the need for urgent diagnosis.

Adenocarcinoma of endometrium is often preceded by endometrial hyperplasia. Thus, early accurate diagnosis and proper treatment of endometrial hyperplasias is mandatory to prevent endometrial carcinoma. 


\section{METHODS}

This is a prospective study done on 65 perimenopausal women with a complaint of AUB in the age group ranging from 40 to 1 year within menopause those are attending to gynaec department Narayana Medical College and Hospital, Nellore, A.P, India from July 2014 to December 2014.

All the patients were included in the study after taking prior informed consent.

\section{Inclusion criteria}

Women with AUB $>40$ yrs and within 1 year of menopause.

\section{Exclusion criteria}

Uterus > 12 weeks size

Hormone therapy within last 6 months

Previous abnormal endometrial biopsy

Positive pregnancy test

Obvious cervical pathology and speculum examination

Abnormal cervical pap smear.

After thorough history taking, clinical examination and exclusion of cervical malignancy by speculum examination and cervical pap smear. An informed written consent was taken from all the eligible patients. Transvaginal ultrasound was done to note endometrial thickness and other pelvic pathologies. All the patients were subjected to either to endometrial biopsy or dilatation and curettage. Endometrial samples were subjected to histopathological examination.

\section{RESULTS}

A total of 65 patients in perimenopausal age were recruited in the present study group. In the present study group of 65 women, $44(67.69 \%)$ women were in age group of 40-45yrs, 17 (26.15\%) were between 46-50yrs of age, and $4(6.25 \%)$ were in between 50-55 yrs age (Table 1). Out of 65 women, $11(16.9 \%)$ were primiparas, $36(55.38 \%)$ were para $2,18(27.69 \%)$ were para 3 and above (Table 2).

Table 1: AUB - age distribution.

\begin{tabular}{|ll|l|}
\hline Age & $n / t$ & $\%$ \\
\hline $40-45$ & $44 / 65$ & 67.69 \\
\hline $46-50$ & $17 / 65$ & 26.15 \\
\hline $50-55$ & $4 / 65$ & 6.15 \\
\hline
\end{tabular}

Menorrhagia observed in $63 \%$, Polymenorrhagia observed in $21.53 \%$, Post-menopausal bleeding observed in $9.23 \%$ and Intermenstrual bleeding observed in $6.15 \%$ (Table 3).
Table 2: AUB - parity.

\begin{tabular}{|lll|}
\hline Parity & $\mathrm{n} / \mathrm{t}$ & $\%$ \\
\hline Para 1 & $11 / 65$ & 16.9 \\
\hline Para 2 & $36 / 65$ & 55.38 \\
\hline Para 3 and above & $18 / 65$ & 27.69 \\
\hline
\end{tabular}

Most common type of endometrial pattern is proliferative endometrium. Out of 65 perimenopausal women, 23 $(35.38 \%)$ had proliferative type of endometrium, 20 (30.76) women had secretory pattern, 9 (13.84 \%) had typical simple endometrial hyperplasia, $4(6.15 \%)$ had atypical simple endometrial hyperplasia, $3(4.61 \%)$ had adenomyomatous polyp, and $6(9.2 \%)$ women had irregular ripening (Table 4) (Figure 1).

Table 3: AUB - bleeding pattern.

\begin{tabular}{|lll|}
\hline Bleeding pattern & $\mathrm{n} / \mathrm{t}$ & $\%$ \\
\hline Menorrhagia & $41 / 65$ & 63 \\
\hline Polymenorrhagia & $14 / 65$ & 21.53 \\
\hline Post-menopausal bleeding & $6 / 65$ & 9.23 \\
\hline Intermenstrual bleeding & $4 / 65$ & 6.15 \\
\hline
\end{tabular}

Among 65 perimenopausal women with AUB, 10 $(15.38 \%)$ women had fibroid, 5 (7.69) had adenomyosis, 2 (3.07) had ovarian cysts (Figure 2).

Table 4: AUB - histopathology of endometrium.

\begin{tabular}{|lll|}
\hline Histologic pattern & $\mathrm{n} / \mathrm{t}$ & $\%$ \\
\hline Proliferative & $23 / 65$ & 35.38 \\
\hline Secretory & $20 / 65$ & 30.76 \\
\hline $\begin{array}{l}\text { Typical simple endometrial } \\
\text { hyperplasia }\end{array}$ & $9 / 65$ & 13.84 \\
\hline $\begin{array}{l}\text { Atypical simple endometrial } \\
\text { hyperplasia }\end{array}$ & $4 / 65$ & 6.15 \\
\hline Adenomyomatous polyp & $3 / 65$ & 4.61 \\
\hline Irregular ripening & $6 / 65$ & 9.2 \\
\hline
\end{tabular}

Among 65 perimenopausal women, 56(86.15\%) had endometrial thickness of 10-20 mm, $6(9.2 \%)$ women had endometrial thickness less than $10 \mathrm{~mm}, 3(4.61 \%)$ had ET 20-25 mm (Figure 3).

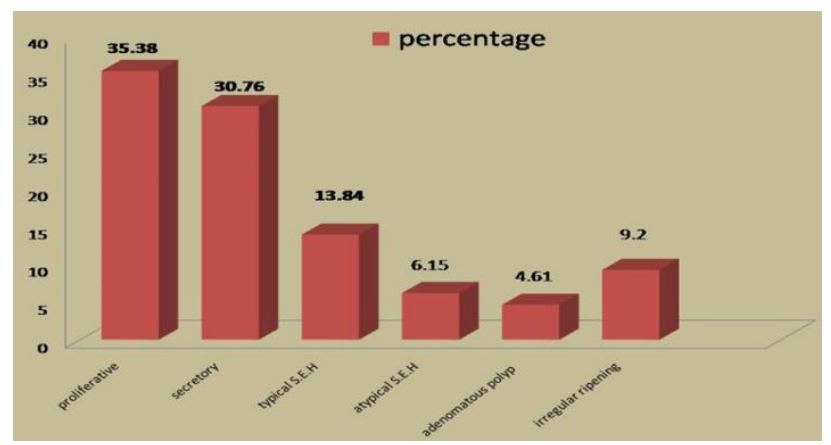

Figure 1: AUB -histopathology of endometrium. 


\section{DISCUSSION}

A total of 65 patients with AUB were included in the present study. In present study group $67.69 \%$ women with AUB are in age group between $40-45$ years which is corresponding to the study done by Sharma N \& Sharma A $(62.5 \%), 25.4 \%$ women were between age groups of 46 -50 years, $6.15 \%$ women were above 50 years which is correlating to Bhavani et al $(6.5 \%)$. The mean age for menstrual abnormalities in present study was 42 years. ${ }^{3,4}$

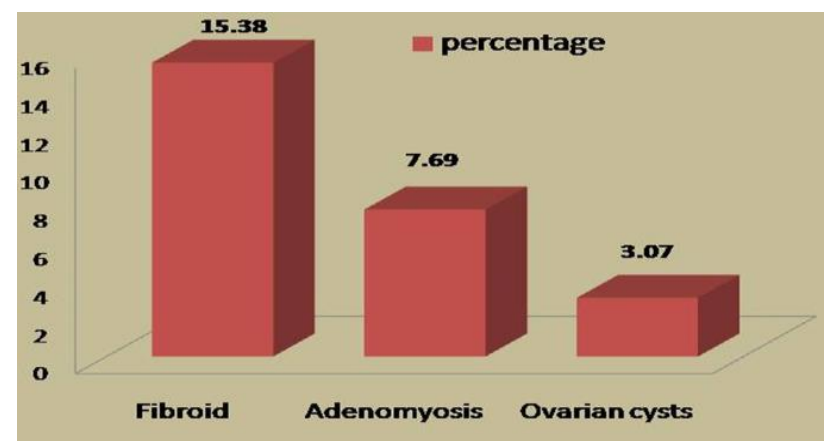

Figure 2: AUB - Structural changes.

In present study group of women with AUB para 1 were of $16.9 \%$ which is correlating with the Gowri $\mathrm{M}$ et al $(17.6 \%) .^{5} 55.38 \%$ women of para 2 which is higher than the study done by Gowri M et al. ${ }^{5} 27.69 \%$ were para 3 and above which is close to study done by Bhavani et al ${ }^{4}$ $(32.5 \%)$. Para 2 women were more in our study compared to other studies because most of the women were undergoing sterilization after two children.

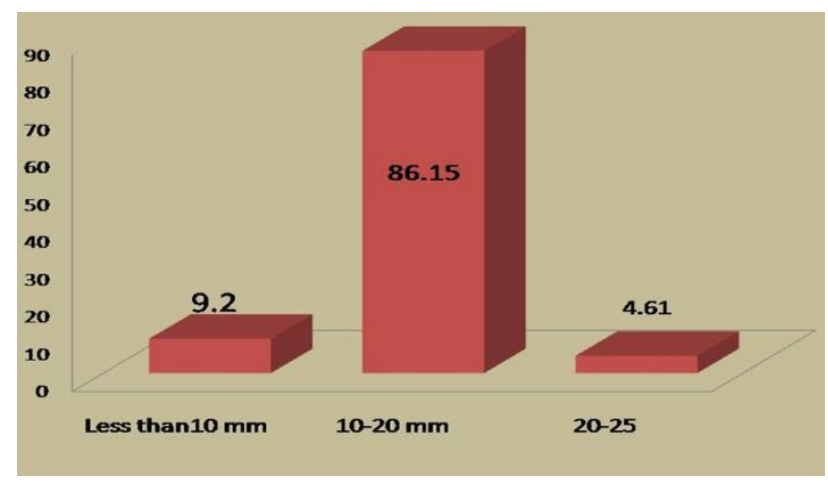

Figure 3: AUB - endometrial thickness.

$63 \%$ Women in perimenopausal age presented with menorrhagia followed by polymenorrhagia in $21.5 \%$, post-menopausal bleeding in $9.2 \%$, intermenstrual bleeding in $6.15 \%$ which is correlating with study done by Avantika et al (menorrhagia $72 \%$, polymenorrhagia $20 \%$, intermenstrual bleeding $8 \%)^{2}$

In our study group of 65 women with AUB, endometrial biopsy report was proliferative phase in $35.38 \%$, secretory phase in $30.76 \%$, endometrial hyperplasia in $19.99 \%$, polyp in $3 \%$ and irregular ripening in $9.2 \%$ which is closely related to study done by Layla Abdullah et al (proliferative $24.4 \%$, secretory $39.6 \%$, hyperplasia $16.9 \%$ and polyp $23.3 \%$ ) and Zehra $\mathrm{Y}$ et al (normal endometrium $52 \%$, endometrial hyperplasia $15 \%)$. ${ }^{6,7}$

In our study group $26.14 \%$ women with AUB had organic pathology like fibroids, adenomyosis and ovarian cyst which is correlating to study done by Devi et al $(22.8 \%){ }^{8}$

In our study group $9.2 \%$ women with AUB had endometrial thickness $<10 \mathrm{~mm}, 86.15 \%$ had ET between $10-20 \mathrm{~mm}$ and $4.61 \%$ had ET between $20-25 \mathrm{~mm}$, all these women had polyp.

\section{CONCLUSIONS}

The present study shows that HPE is mandatory in all cases of AUB in perimenopausal age. $66.14 \%$ had benign pathology which can be managed by hormonal therapy or conservative surgical modalities which alleviates need for unnecessary hysterectomy.

\section{Funding sources:}

Conflict of interest: None declared

Ethical approval: The study was approved by the Institutional Ethics Committee

\section{REFERENCES}

1. Shwetha A, Asha M, Vaishnav K. Histopathological study of endometrium in abnormal uterine bleeding in women of all age groups in western rajasthan (400 cases). Int J Basic App Med Sci. 2014;4(3):15-8.

2. Avantika G, Asmita MR, Usha M,Poonam R. Evaluation and histopathological correlation of abnormal uterine bleeding in perimenopausal women. Int J Biomed Advanced Res. 2013;04(08):509-13.

3. Sharma N, Sharma A. Thyroid profile in menstrual disorders. JK Science. 2012;14(1):14-7.

4. Bhavani N, Avanthi S, Aradhana G, Sangeeta Ch, Prasannakumar VS. A study of correlation between abnormal uterine bleeding and thyroid dysfunction. Int J Recent Trends Sci Tech. 2015;14(1):131-5.

5. Gowri M, Radhika BH, Harshini V, Renuka R. Role of thyroid function tests in women with abnormal uterine bleeding. Int $\mathbf{J}$ Reprod Contracept Obstet Gynecol. 2014;3(1):54-7.

6. Layla SA, Nabel SB. Histopathological pattern of endometrial sampling performed for abnormal uterine bleeding. Bahrain Medical Bulletin. 2011;33(4):1-6.

7. Zehra Y, Elif AY, Bulent C, Ismail BG, Mehmet FK, Yasemin $\mathrm{C}$, et al. Correlation of bleeding pattern with histopathological results in perimenopausal women with abnormal uterine bleeding. Int J Reprod Contracept Obstet Gynecol. 2015;4(3):547-50. 
8. Devi J, Aziz N. Study of histopathological pattern of endometrium in abnormal uterine bleeding in the age group 40-60 years - A study of 500 cases. Int $\mathrm{j}$ med sci clin invent. 2014;1(10):579-85.
Cite this article as: Byna $\mathrm{P}$, Siddula $\mathrm{S}$, Kolli $\mathrm{S}$, Shaik MV. Histopathological correlation of abnormal uterine bleeding in perimenopausal women Int $\mathrm{J}$ Reprod Contracept Obstet Gynecol 2015;4:1875-8. 